\title{
The Incorporation of Bovine Serum Albumin Into a Polypyrrole Film in One Simple Step
}

\author{
Anita Hamilton ${ }^{\mathrm{a}}$ and Carmel Breslin ${ }^{\mathrm{a}}$ \\ ${ }^{a}$ Department of Chemistry, National University of Ireland Maynooth, Maynooth, Co. \\ Kildare, Ireland.
}

\begin{abstract}
The model protein, bovine serum albumin (BSA), was successfully incorporated into a polypyrrole film in one simple electropolymerisation step. The presence of BSA within the polymer was established using scanning electron microscopy, coupled with energy dispersive X-ray analysis; additionally, cyclic voltammetry and electrochemical impedence spectroscopy were utilised to investigate differences between the polymer films in the presence and absence of the BSA and to determine the capacitance of the polymers. It was found that the presence of BSA within polypyrrole reduces the electroactivity of the polymer and has a fibrous surface morphology compared to the characteristic cauliflower morphology of PPy-Cl.
\end{abstract}

\section{Introduction}

Bovine serum albumin, commonly referred to as BSA, is the most abundant protein in the circulatory system and contributes to over $80 \%$ of the colloidal osmotic blood pressure (1). It has been determined that serum albumin is chiefly responsible for the maintenance of the blood $\mathrm{pH}$ (2). Because of this, a lot of research has been carried out in order to identify the structure and properties of serum albumin and, to investigate the effect serum albumin has on the functionality of foods in which it is included, as well as other novel applications.

Although human serum albumin (HSA) and BSA share $80 \%$ of their sequence homology, have identical isoelectric points of 4.77 (3) and their molecular weights differ by less than $1 \%$ (4), HSA has a unique tryptophan at position 132, whereas BSA contains two tryptophan moieties at positions 134 and 212 as well as tyrosine and phenylalanine (5). Due to its water-soluble nature, BSA is used as a model protein for interaction studies.

BSA has been considered as a soft protein, as it has a high potential to undergo structural rearrangements upon adsorption onto surfaces (6) and, as such, it is promising in the area of sensors and biosensors. The first crucial issue for BSA sensors is the attachment or immobilisation of the BSA onto the electrode. The most commonly used method of immobilisation is the covalent binding technique as it can artificially bind the target which forms an ordered and dense monolayer (7). In recent years however, sol-gel chemistry has been used as a more effective method for the immobilisation of proteins due to the low temperature mechanism required for immobilisation in contrast to the traditional covalent binding mechanism, which can often denature the proteins. The 
covalent immobilisation of functional, biological species such as BSA into a sol-gel matrix or onto a suitable surface such as titanium dioxide provides numerous applications for in vitro studies on the behaviour of biological structures and biosensors (8). Along with this, BSA can be incorporated into hydrogels (9) and nano-composites $(8,10)$, which has led to numerous applications in both drug delivery systems and in the area of biosensors.

Other immobilisation methods that have been used to immobilise BSA have been investigated by Soldatkin et al. (11) whereby a biologically active membrane on the transducer surface was formed by protein cross-linking in saturated glutaraldehyde vapour. Similarly, Im and co-workers (12) electrodeposited a mixture of glucose oxidase and BSA onto a Pt electrode and subsequently cross-linked with glutaraldehyde to form a glucose amperometric biosensor with good sensing behaviour. Another method of immobilising BSA is to incorporate it into self-assembled monolayers (SAMs). Ignat et al. (13) have investigated the organisation of SAMs of functionalised thiols and the incorporation of various proteins onto gold and silicon substrates for their potential integration in nanoscale sensors/biosensors and optical devices. The authors claim that the biomolecule immobilisation of the proteins by covalent chemistry allows for the fabrication of reproducible, protein-modified surfaces, which is in good agreement with the literature. However, to the best of our knowledge, there is little evidence in the literature to support the immobilisation of BSA into a polymer film in one simple step.

\section{Experimental}

\section{$\underline{\text { Chemicals }}$}

The chemicals used throughout this study were purchased from Sigma-Aldrich or its subsidiary company Fluka. All chemicals were used as supplied expect for pyrrole which was vacuum-distilled and stored in the dark at $-20{ }^{\circ} \mathrm{C}$ prior to use. All other solutions were made from a stock solution of $0.10 \mathrm{~mol} \mathrm{dm}^{-3} \mathrm{NaCl}$, which was initially prepared using distilled water. The bovine serum albumin solution as provided was very viscous, as such, this was diluted down using a $0.10 \mathrm{~mol} \mathrm{dm}^{-3} \mathrm{NaCl}$ solution; all concentrations of BSA are hence given as the volume of BSA (in $\mu \mathrm{L}$ ) in $10 \mathrm{~mL}$ of $0.10 \mathrm{~mol} \mathrm{dm}^{-3} \mathrm{NaCl}$. All of the solutions were freshly prepared before each experiment. Where necessary, the $\mathrm{pH}$ of the solutions was altered using concentrated $\mathrm{HCl}$ or $\mathrm{NaOH}$.

\section{$\underline{\text { Instrumentation }}$}

Potentiostatic and cyclic voltammetry experiments were carried out using a Solartron Potentiostat Model 1287. The impedance experiments were carried out using a Solartron Frequency Response Analyser Model 1255B, in conjunction with the Solartron Potentiostat Model 1287. All measurements were performed at room temperature (approximately $25{ }^{\circ} \mathrm{C}$ ) in a standard three-electrode cell with a platinum $(\mathrm{Pt})$ working electrode, a high surface area platinum wire counter electrode and a SCE reference electrode. The Pt electrodes ( $4 \mathrm{~mm}$ in diameter) were encased in a larger Teflon ${ }^{\circledR}$ sheath and set in place using a non-conducting epoxy resin. The electrical contact was made with a copper wire attached using a highly conducting silver-loaded resin. The working 
electrodes were polished to a smooth surface, mirror finish, using 30, 15, 6 and $1 \mu \mathrm{m}$ diamond suspensions on microcloth (Buehler), sonicated in distilled water and then in ethanol to remove any polishing residues, and finally rinsed with distilled water and dried.

\section{Fabrication of the BSA immobilised into polypyrrole (PPy) films}

The BSA was immobilised into the polypyrrole (PPy) films in a single-step process. The films were electrochemically prepared onto the platinum working electrode from an aqueous solution containing pyrrole monomer $\left(0.50 \mathrm{~mol} \mathrm{dm}^{-3}\right)$, BSA $(25-200 \mu \mathrm{L})$ and $\mathrm{NaCl}\left(0.10 \mathrm{~mol} \mathrm{dm}^{-3}\right)$ at a fixed potential of $0.70 \mathrm{~V}$ vs. SCE. The polymer films were deposited until a fixed charge of $0.01-0.74 \mathrm{C} \mathrm{cm}^{-2}$ was achieved. The thickness of the films obtained was approximated as between $1-30 \mu \mathrm{m}$, which was theoretically calculated using the charge thickness ratio derived by Diaz et al. (14) for a simple chloride dopant. In this analysis it is assumed that $1.0 \mathrm{C} \mathrm{cm}^{-2}$ of charge passed is equivalent to $2.5 \mu \mathrm{m}$ of polymer film. It is important to mention that the theoretical values of thickness obtained for the PPy-BSA film are only an approximation, as the films doped with the large biological entity may not have the same charge to polymer thickness ratio as the PPy-Cl films $(15,16)$.

Characterisation of the BSA immobilised into polypyrrole (PPy) films

The PPy-BSA films were characterised using cyclic voltammetry (CV), scanning electron microscopy coupled with energy dispersive X-Ray analysis (SEM and EDX) and electrochemical impedance spectroscopy (EIS). The cyclic voltammetry measurements were recorded at $50 \mathrm{mV} \mathrm{s}^{-1}$ in the potential interval of -0.90 to $0.90 \mathrm{~V}$ vs. SCE. The EIS measurements were carried out in a solution of $0.10 \mathrm{~mol} \mathrm{dm}^{-3} \mathrm{NaCl}$ and the polymer film was initially conditioned for $30 \mathrm{~min}$ at a fixed applied potential, to ensure that a steady state was reached before measurements were performed. The impedance data were then recorded, initially from high to low frequencies, then reversing the sweep and recording the data from low to high frequencies. A potential perturbation of $5 \mathrm{mV}$ was used to ensure a pseudo-linear response of the system, while the frequency was varied from 65 $\mathrm{kHz}$ to $100 \mathrm{mHz}$.

\section{Results and Discussion}

\section{Formation of PPy-BSA using a potentiostatic mode}

The PPy-BSA polymer film was formed as described previously by applying a fixed potential of $0.70 \mathrm{~V}$ vs. SCE to a monomer solution containing varied quantities of BSA, ranging from 25 to $200 \mu \mathrm{L}$. In Figure 1, current-time plots are shown for increasing concentrations of BSA, while for comparative purposes, the plot recorded in the absence of BSA, is included.

On application of the potential, there is an initial rapid decrease in the current, which arises from the charging of the double layer. This charging current decays rapidly, being governed by the RC time constant, which is related to the size of the electrode and the conductivity of the solution (17). This is then followed by a slower rise, at about $2-5 \mathrm{~s}$, 
as the polypyrrole film begins to nucleate and deposit at the surface of the working electrode. There is a further more gradual increase in the current as the polymer becomes deposited onto the working electrode.

It can be seen from Figure 1 that as the BSA concentration is increased, the current density recorded during electropolymerisation is reduced. This is due to the size and viscosity of the BSA. The BSA is a large globular protein that inhibits access of the monomer to the electrode surface (18). This is very evident during the first few seconds of electropolymerisation, where the rate at which the current increases is considerably reduced in the presence of the BSA. Indeed, for the higher BSA concentrations, the current only increases after a considerable time period, typically $50 \mathrm{~s}$, giving an induction period. This is consistent with a reduction in the concentration of the radical cations, dimers and other short chain oligomers that are generated during the oxidation of the pyrrole (19). Longer time periods are required to generate a sufficient concentration of the cations and dimers and the deposition of the conducting polypyrrole film with increasing concentrations of BSA.

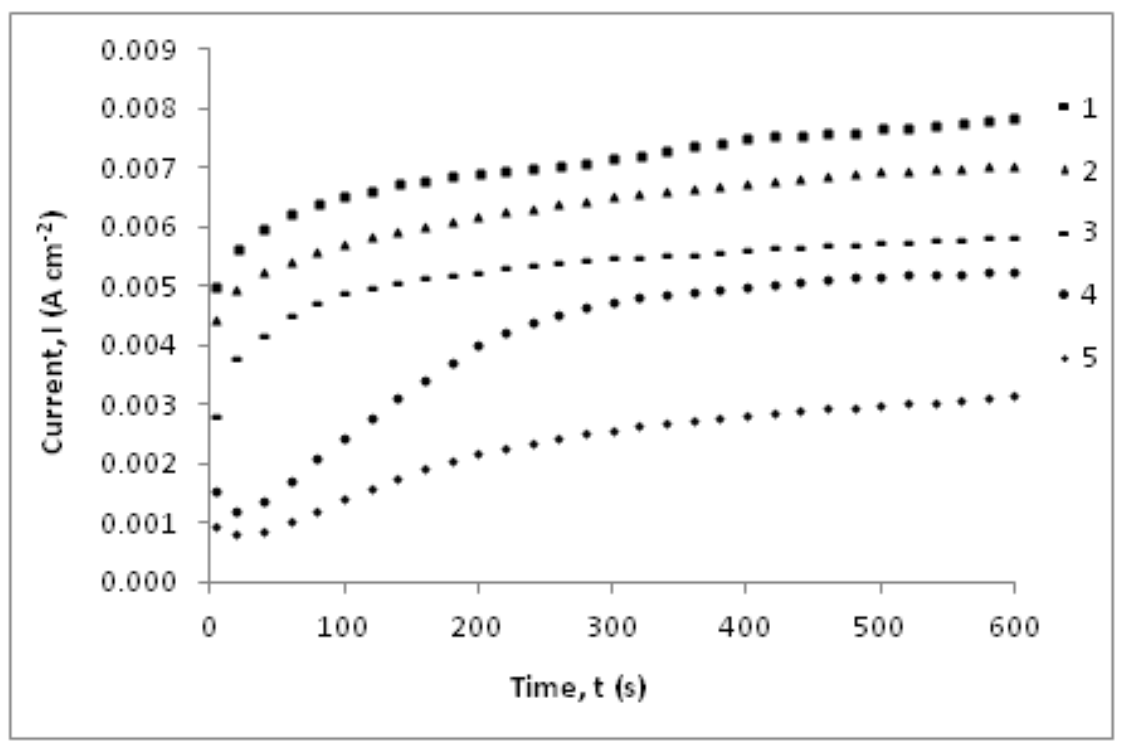

Figure 1. Current- time plots for the formation of PPy-Cl and PPy-BSA on a Pt electrode at $0.70 \mathrm{~V}$ vs. SCE from a solution containing $0.10 \mathrm{~mol} \mathrm{dm}^{-3} \mathrm{NaCl}$ and $\mathbf{- 1} 0.50 \mathrm{~mol} \mathrm{dm}^{-3}$ pyrrole, $\boldsymbol{\Delta} 20.50 \mathrm{~mol} \mathrm{dm}^{-3}$ pyrrole $/ 25 \mu \mathrm{L} \mathrm{BSA}, \mathbf{- 3} 0.50 \mathrm{~mol} \mathrm{dm}^{-3}$ pyrrole $/ 50 \mu \mathrm{L} \mathrm{BSA}$, $\bullet 40.50 \mathrm{~mol} \mathrm{dm}^{-3}$ pyrrole $/ 100 \mu \mathrm{L}$ BSA and $\$ 50.50 \mathrm{~mol} \mathrm{dm}^{-3}$ pyrrole $/ 200 \mu \mathrm{L}$ BSA.

\section{Characterisation of the PPy-BSA using cyclic voltammetry}

The PPy-BSA (and PPy-Cl as a comparison) films were characterised by cycling them in a solution of $0.10 \mathrm{~mol} \mathrm{dm}^{-3} \mathrm{NaCl}$. The cyclic voltammograms recorded are shown in Figure 2 for the $\mathrm{PPy}-\mathrm{Cl}$ and $\mathrm{PPy}-\mathrm{BSA}$ films formed from solutions containing 25 to $200 \mu \mathrm{L}$ BSA. It is evident from Figure 2 that the $\mathrm{PPy}-\mathrm{Cl}$ film has a higher current density than the PPy-BSA films, which is consistent with the more insulating nature of the PPy-BSA (20). Indeed, as the BSA concentration in the electropolymerisation 
solution is increased to give higher loadings of BSA within the polymer matrix, there is a further decrease in the measured currents. This is clearly evident in the vicinity of the oxidation wave, where the peak oxidation currents decrease with an increase in the BSA concentration. It is apparent from Figure 2 that the electroactivity of the polymer film is greatly reduced with increasing BSA concentration. Again, this can be accounted for by the fact that BSA is a large, globular protein that blocks the pores of the polymer film, thus decreasing the electroactivity of the polymer (18).

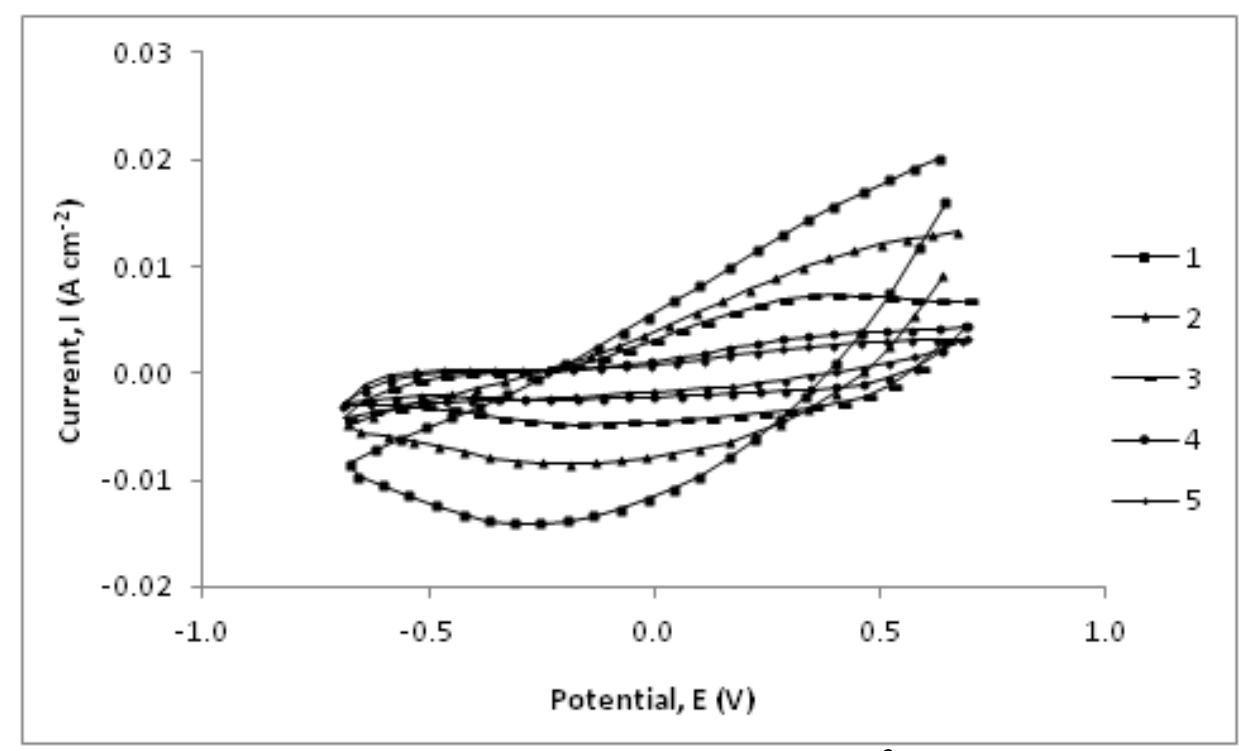

Figure 2. Cyclic voltammograms recorded in $0.10 \mathrm{~mol} \mathrm{dm}^{-3} \mathrm{NaCl}$ solution, $\mathrm{pH} 7.0$, from -0.70 up to $0.70 \mathrm{~V}$ vs. SCE for the PPy-Cl $(0.74 \mathrm{C})$ and PPy-BSA $(0.74 \mathrm{C})$ films electropolymerised on a Pt electrode at $0.70 \mathrm{~V}$ vs. SCE from a solution containing 0.10 mol dm${ }^{-3} \mathrm{NaCl}$ and $\mathbf{\square 1} 0.50 \mathrm{~mol} \mathrm{dm}^{-3}$ pyrrole, $\boldsymbol{\Delta} 20.50 \mathrm{~mol} \mathrm{dm}{ }^{-3}$ pyrrole/25 $\mu \mathrm{L} \mathrm{BSA}, \mathbf{- 3}$ $0.50 \mathrm{~mol} \mathrm{dm}^{-3}$ pyrrole $/ 50 \mu \mathrm{L}$ BSA, $\bullet 40.50 \mathrm{~mol} \mathrm{dm}^{-3}$ pyrrole/100 $\mu \mathrm{L}$ BSA and $\bullet \mathbf{5} 0.50$ mol dm ${ }^{-3}$ pyrrole/200 $\mu$ L BSA.

\section{Characterisation of the PPy-BSA using SEM and EDX}

The physical morphologies of the $\mathrm{PPy}-\mathrm{Cl}$ and $\mathrm{PPy}-\mathrm{BSA}$ polymer films were characterised by scanning electron microscopy. A typical SEM micrograph of PPy-Cl can be observed in Figure 3a, with the characteristic cauliflower morphology of polypyrrole evident (21). In contrast, Figure $3 \mathrm{~b}$ shows an SEM micrograph of the PPyBSA polymer film, which exhibits a highly fibrous morphology. This indicates the presence of the globular BSA within the polypyrrole film. 
(a)

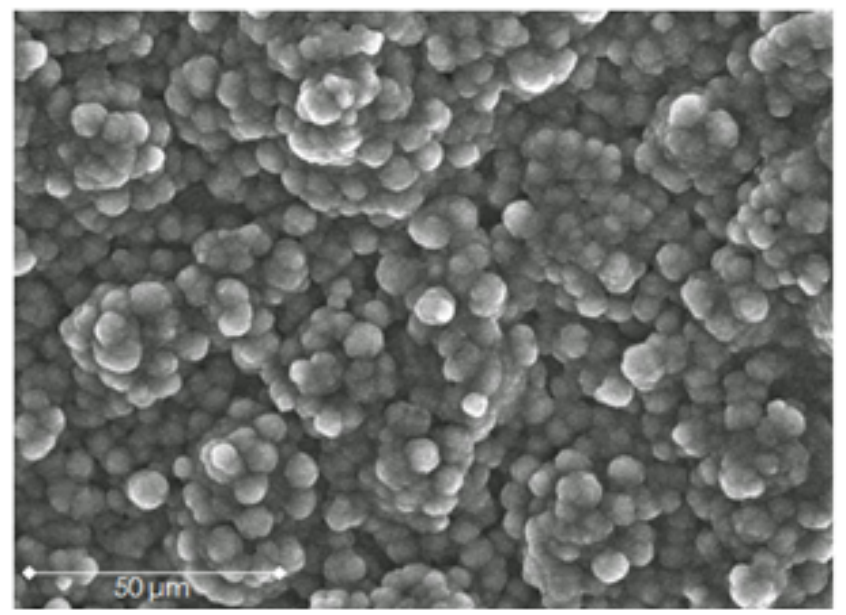

(b)

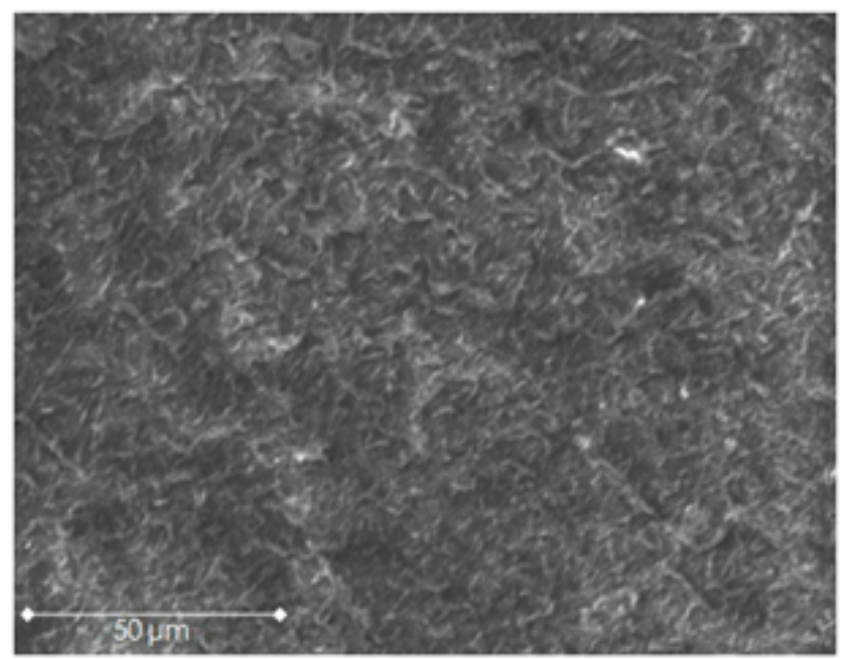

Figure 3. Scanning electron micrograph of the polymer films electrosynthesised at 0.70 $\mathrm{V}$ vs. SCE from a solution containing (a) $0.50 \mathrm{~mol} \mathrm{dm}^{-3}$ pyrrole and $0.10 \mathrm{~mol} \mathrm{dm}^{-3} \mathrm{NaCl}$ for the PPy-Cl film and (b) $0.50 \mathrm{~mol} \mathrm{dm}^{-3}$ pyrrole, $50 \mu \mathrm{L} \mathrm{BSA}$ and $0.10 \mathrm{~mol} \mathrm{dm}^{-3} \mathrm{NaCl}$ for the PPy-BSA film until a charge of $10.48 \mathrm{C} \mathrm{cm}^{-2}$ was reached.

EDX measurements were also performed on the PPy-Cl and PPy-BSA films. The EDX spectrum of the PPy-Cl polymer, Figure $4 \mathrm{a}$, shows the presence of a large quantity of chloride anions in the polymer film. The absence of a sodium signal shows that the chloride anions are present as dopants. The EDX spectrum of the PPy-BSA film, Figure $4 \mathrm{~b}$, shows that although some chloride is present in the polymer film, sulphur is also present. Again, no sodium is observed and this provides direct evidence for the incorporation of the BSA as the signal is due to the presence of disulphide bonds in the BSA $(6,22)$. The oxygen signal, which arises from the amino acids, is also consistent with the incorporation of BSA within the polymer matrix. The presence of the chloride in the PPy-BSA film proves that the chloride ions from the $0.10 \mathrm{~mol} \mathrm{dm}{ }^{-3} \mathrm{NaCl}$ used as the supporting electrolyte are incorporated into the polymer film as dopants during polymerisation to counteract the positive charge that is generated on the oxidised polypyrrole backbone $(23,24)$. 
(a)

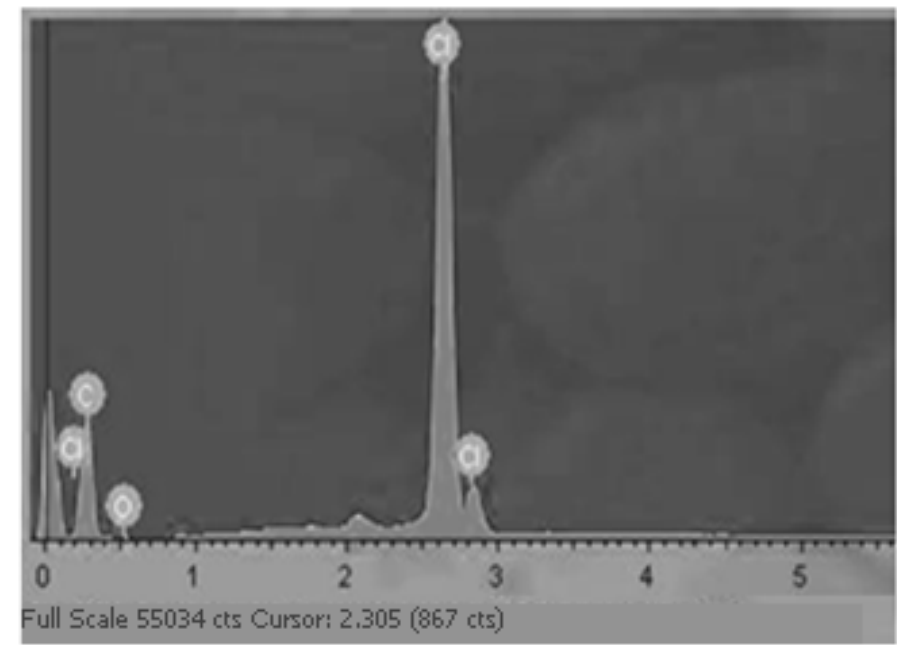

(b)

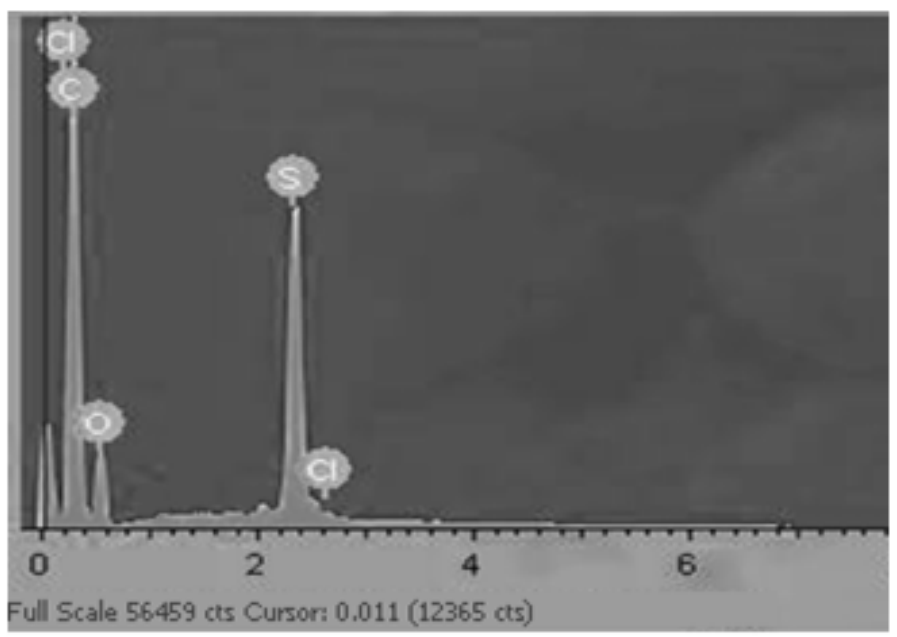

Figure 4. Energy-dispersive X-Ray spectrum of a PPy-BSA film electrodeposited with an applied potential of $0.70 \mathrm{~V}$ vs. SCE until a charge of $10.48 \mathrm{C} \mathrm{cm}^{-2}$ was reached from a solution containing (a) $0.50 \mathrm{~mol} \mathrm{dm}^{-3}$ pyrrole and $0.10 \mathrm{~mol} \mathrm{dm}^{-3} \mathrm{NaCl}$ for the PPy-Cl film and (b) $0.50 \mathrm{~mol} \mathrm{dm}{ }^{-3}$ pyrrole, $50 \mu \mathrm{L} \mathrm{BSA}$ and $0.10 \mathrm{~mol} \mathrm{dm}^{-3} \mathrm{NaCl}$ for the PPy-BSA film.

\section{Analysis of the Polymer Films using EIS}

EIS measurements were carried out on the $\mathrm{PPy}-\mathrm{Cl}$ and PPy-BSA polymer films at applied potentials from -0.10 to $0.90 \mathrm{~V}$ vs. SCE. Prior to the measurements, the films were preconditioned for $30 \mathrm{~min}$ at the applied potential in the same solution. This conditioning period was sufficiently long to achieve steady-state conditions. The steadystate condition was verified by recording the impedance data from high to low frequencies and then from low to high frequencies (25). In all cases, identical data were recorded, indicating steady-state conditions were reached.

Representative Nyquist and Bode plots are presented in Figure 5 for the $\mathrm{PPy}-\mathrm{Cl}$ and PPy-BSA films recorded in $0.10 \mathrm{~mol} \mathrm{dm}^{-3} \mathrm{NaCl}$ at $0.50 \mathrm{~V}$ vs. SCE. The modulus of the impedance, $\mathrm{Z}$, and the phase angle, presented as a function of the frequency, gives the Bode plot, while the imaginary and real components of the impedance are plotted to give 
the Nyquist or complex plane. In all cases, the impedance data were recorded as a function of the immersion time at the fixed potential.

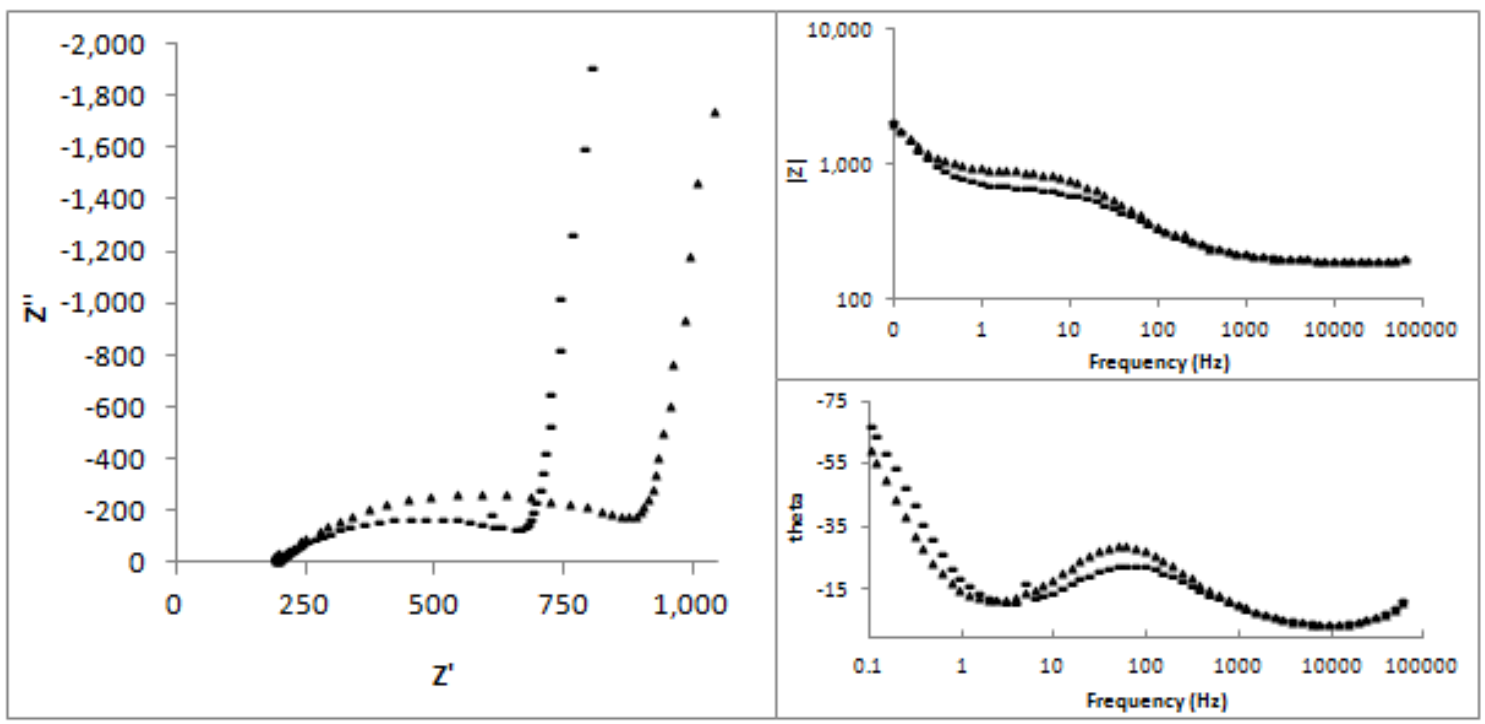

Figure 5. The Nyquist and Bode plots (with $\mathrm{Z}$ in units of $\Omega \mathrm{cm}^{2}$ ) recorded for the $\mathbf{\Delta} \mathbf{\Delta} \boldsymbol{\Delta}$ PPy-Cl and - PPy-BSA films in $0.10 \mathrm{~mol} \mathrm{dm}^{-3} \mathrm{NaCl}$ at an applied potential of $0.50 \mathrm{~V}$ vs. SCE.

It is evident from Figure 5 that the $\mathrm{PPy}-\mathrm{Cl}$ and $\mathrm{PPy}-\mathrm{BSA}$ polymer films have similar impedance profiles, however the diameter of the depressed semicircle is higher for the PPy-BSA film, indicating a higher film resistance. At lower frequencies, a sharp increase in the imaginary impedance is observed, giving a diffusion-like tail. However, the phase angle approaches $90^{\circ}$ indicating a process that is not purely diffusion controlled, but is more complex. The impedance data were fitted to the equivalent circuit depicted in Figure 6, which corresponds to a two-time constant model. The model contains the solution resistance, Rs, the charge-transfer resistance, R1, and two constant phase elements, CPE1 and CPE2.

The impedance data were collected as a function of time and fitted to the circuit in Figure 8 to extract the charge-transfer resistance, R1, and the capacitance and distorted capacitance. The time-dependent behaviour of the charge-transfer resistance is illustrated in Figure 7. At an applied potential of $0.50 \mathrm{~V}$ vs. SCE, the PPy-Cl and PPy-BSA films are oxidised. PPy is well known to have high electronic conductivity in the oxidised or even slightly oxidised states (26). Accordingly, the electronic resistance is negligible under these conditions and the resistance denotes the resistance to ion transfer at the polymer boundary and the intrinsic charge transfer resistance. Interestingly, the resistance remains essentially constant for the $\mathrm{PPy}-\mathrm{Cl}$ film; however, there is a significant increase in the resistance of the PPy-BSA with continued polarisation at $0.50 \mathrm{~V}$ vs. SCE in the chloride-containing electrolyte. These increasing resistance values may be related to conformational changes, solvent and electrolyte uptake within the film and indicate the evolution of the film to a more insulating state. The capacitance of the PPy-Cl film was computed as $4 \mathrm{mF} \mathrm{cm}^{-2}$; however, a lower capacitance is observed for the PPy-BSA film in the region of $1.5 \mathrm{mF} \mathrm{cm}^{-2}$. 


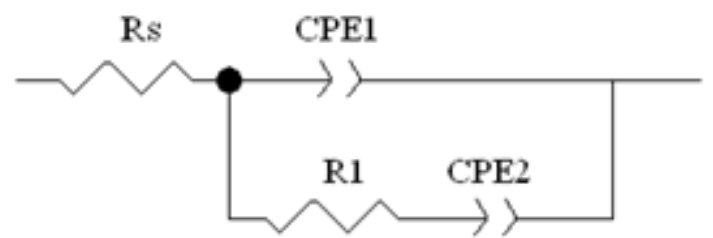

Figure 6. The equivalent electrochemical circuit used to fit impedance data for the PPy$\mathrm{Cl}$ and PPy-BSA polymer films.

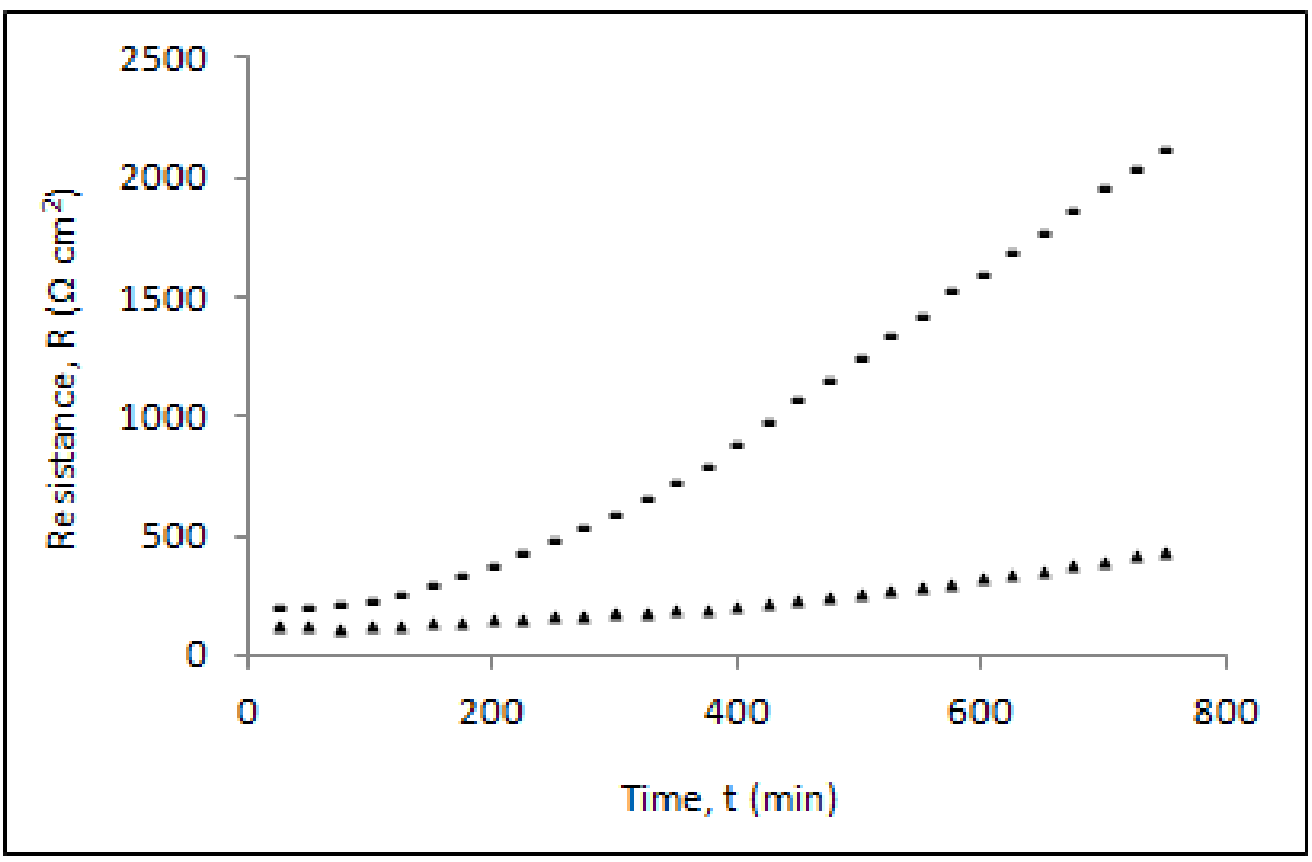

Figure 7. A plot of the charge transfer resistance recorded as a function of time at $0.50 \mathrm{~V}$ vs. SCE for the $\boldsymbol{\Delta} \boldsymbol{\Delta} \Delta \mathrm{PPy}-\mathrm{Cl}$ and $-\mathrm{PPy}-\mathrm{BSA}$ polymer films.

The capacitance of both the PPy-Cl and PPy-BSA films was also calculated by cyclic voltammetry using Equation 1, where $\mathrm{C}$ is the capacitance, $I$ is the current density (A $\left.\mathrm{cm}^{-2}\right)$ and $d V / d t$ is the scan rate $\left(\mathrm{Vs}^{-1}\right)(26)$.

$$
C=\frac{1}{d V}
$$

To obtain a realistic and correct capacitance, the PPy-Cl and PPy-BSA films were cycled in $0.10 \mathrm{~mol} \mathrm{dm}^{-3} \mathrm{NaCl}$ solution at various scan rates, with a lower potential limit of $0.10 \mathrm{~V}$ vs. SCE and an upper potential limit of $0.20 \mathrm{~V}$ vs. SCE. This small electrochemical window was chosen in order to avoid the effects of any faradic currents (27), and the current was obtained at a fixed potential of $0.17 \mathrm{~V}$ vs. SCE.

The capacitance was found to be in the region of $2.25 \times 10^{-3}$ and $1.47 \times 10^{-3} \mathrm{~F} \mathrm{~cm}^{-2}$ for the PPy-Cl and PPy-BSA polymer films, respectively. This is typical of the high capacitance values recorded for conducting polymers (28), and is in good agreement with the values obtained using electrochemical impedence spectroscopy. 


\section{Effect of $\mathrm{pH}$ on the $\mathrm{PPy}-\mathrm{Cl}$ and PPy-BSA Polymers}

The effect of $\mathrm{pH}$ on the stability of both the PPy-Cl and PPy-BSA polymer films was investigated. The polymers were formed at a constant potential of $0.70 \mathrm{~V}$ vs. SCE, then rinsed in distilled water and transferred to a solution of $0.10 \mathrm{~mol} \mathrm{dm}^{-3} \mathrm{NaCl}$ at $\mathrm{pH}$ values ranging from a $\mathrm{pH}$ of 2.0 to a $\mathrm{pH}$ of 12.0. The $\mathrm{pH}$ of the solutions was altered by adding, dropwise, a solution of $\mathrm{HCl}$ to make the solution more acidic, or $\mathrm{NaOH}$ to make the solution more alkaline. The final $\mathrm{NaCl}$ solutions were adjusted to $\mathrm{pH}$ values of 2.0, 4.0, 7.0, 9.0 and 12.0, enabling a full $\mathrm{pH}$ study to be undertaken for both the PPy-Cl and PPyBSA films.

The cyclic voltammograms recorded at a $\mathrm{pH}$ of 7.0 are shown in Figure 2 for the PPy$\mathrm{Cl}$ and PPy-BSA films formed from solutions containing 25 to $200 \mu \mathrm{L}$ BSA. It is evident from Figure 2 that the PPy-Cl film has a higher current density than the PPy-BSA films at a neutral $\mathrm{pH}$, which is consistent with the more insulating nature of the PPy-BSA (20). Indeed, as the BSA concentration in the electropolymerisation solution is increased to give higher loadings of BSA within the polymer matrix, there is a further decrease in the measured currents. This is more apparent in Figure 8a, where the oxidation current measured at a fixed potential of $0.60 \mathrm{~V}$ vs. SCE is plotted as a function of the cycle number for PPy-Cl and PPy-BSA prepared from 50 and $200 \mu \mathrm{L}$ BSA. The current is significantly higher for the $\mathrm{PPy}-\mathrm{Cl}$ film. It is also evident that the three polymer films are stable at this $\mathrm{pH}$; there is no or little change in the current. The current increases slightly from the first to the third cycle, but then remains constant.

Good stability was also observed at $\mathrm{pH}$ values of 2.0, 4.0 and 9.0 and the cyclic voltammograms and current densities are similar, with the $\mathrm{pH}$ having little influence from a $\mathrm{pH}$ of 2.0 to 9.0. BSA undergoes structural conformation changes, with its loops folding and unfolding at different $\mathrm{pH}$ values, providing changes in the surface charge distribution over the species. The predominant, compact form of BSA at a neutral $\mathrm{pH}$ is the normal or ' $\mathrm{N}$ ' form; this unfolds to the ' $\mathrm{F}$ ' (fast migration) form as the $\mathrm{pH}$ is decreased to below $\mathrm{pH} 4$. At more acidic $\mathrm{pH}$ values, the BSA unfolds further to the expanded ' $\mathrm{E}$ ' form, which is fully reversible. At more basic $\mathrm{pH}$ values, BSA changes conformation to the basic ' $\mathrm{B}$ ' form, which undergoes further isomerisation at $\mathrm{pH} 9$ or greater to the alkaline ' $A$ ' form. However, this is also fully reversible and therefore, BSA is stable over a wide range of $\mathrm{pH}$ values, which is connected with the similar currents observed in Figure 8a. Nevertheless, at a $\mathrm{pH}$ of 12.0, the currents obtained from the voltammograms were considerably lower and after cycle 5 there is evidence of a further drop in the current, Figure 8b, indicating poor stability in this highly alkaline solution. This is due to a loss in conductivity $(29,30)$, to give more insulating polymer films and the decrease in current could arise from both the nature of the polymer film and the BSA $(31,32)$. 

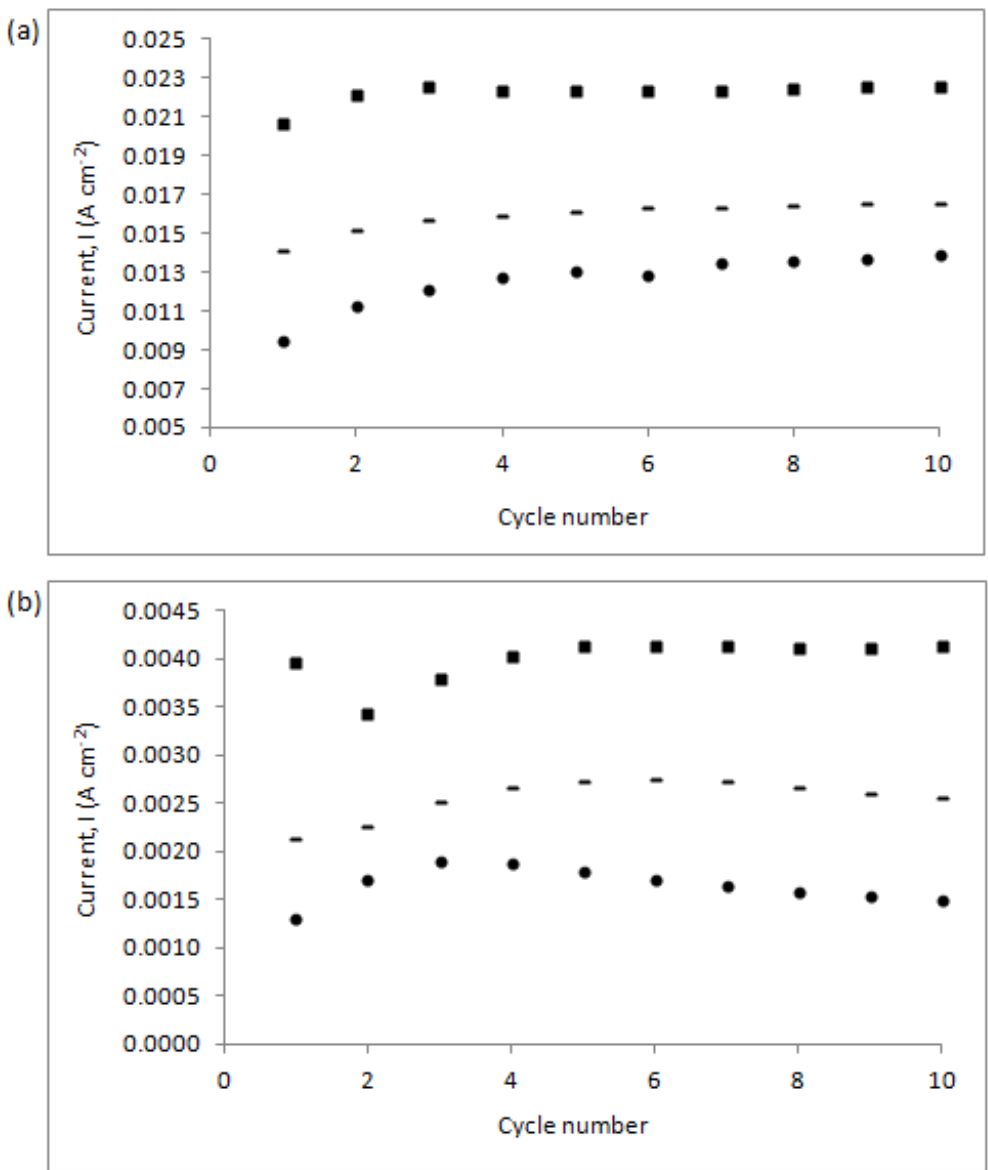

Figure 8. The current obtained at a fixed potential of $0.60 \mathrm{~V}$ vs. SCE plotted as a function of cycle number, for cycling the ma PPy-Cl, - PPy-BSA (50 $\mu \mathrm{L}$ BSA) and $\bullet \bullet \bullet P P y-B S A(200 \mu \mathrm{L} \mathrm{BSA})$ polymer films in $0.10 \mathrm{~mol} \mathrm{dm}^{-3} \mathrm{NaCl}$ at a $\mathrm{pH}$ of (a) 7.0 and (b) 12.0 .

\section{Conclusions}

This study has demonstrated that it is indeed possible to immobilise a large, globular protein such as BSA into a polypyrrole matrix in one simple step. A high concentration of pyrrole was used to facilitate access of the monomer to the electrode surface during polymer formation. The presence of the BSA within the polymer film was confirmed using SEM and EDX analysis; additionally, CV and EIS were utilised to investigate differences between the polymer films in the presence and absence of the BSA. The BSA within the polymer film proved to be stable over a wide $\mathrm{pH}$ range, from $\mathrm{pH} 2.0$ to $\mathrm{pH} 9.0$, but the polymer film suffered from a loss in conductivity at higher $\mathrm{pH}$ values. The low cost and simple method of immobilising the BSA within the polypyrrole film has many advantages in that the free $\mathrm{NH}_{2}$ groups on the BSA may be used to immobilise enzymes or other proteins by cross-linking them to the BSA and hence, the PPy-BSA can be used for a wide variety of sensing applications. 


\section{Acknowledgments}

The authors would like to thank the Irish Research Council for the financial support received for this project.

\section{References}

1. D. C. Carter and J. X. Ho, Structure of Serum Albumin. Adv. Protein Chem., 45, 153, (1994).

2. J. Figge, T. H. Rossing, and V. Fencl, The Role of serum-proteins in Acid-Base Equilibria, J. Lab. Clin. Med., 117, 453, (1991).

3. B. Lu, S.-B. Xiong, H. Yang, X.-D. Yin and R.-B. Zhao, Int. J. Pharm., 307, 168, (2006).

4. T. Mogues, J. Li, J. Coburn and D. J. Kuter, J. Immunol. Methods, 300, 1, (2005).

5. A. Ravindran, A. Singh, A. M. Raichur, N. Chandrasekaran and A. Mukherjee, Colloids Surf. B., 76, 32, (2010).

6. R. Tantipolphan, T. Rades, A. J. McQuillan and N. J. Medlicott, Int. J. Pharm., 337, 40, (2007).

7. Y. Wang, X. Yin, M. Shi, W. Li, L. Zhang and J. Kong, Talanta, 69, 1240, (2006).

8. C. K. Simi and T. E. Abraham, Colloids Surf. B., 71, 319, (2009).

9. J.-C. Gayet and G. Fortier, J. Controlled Release, 38, 177, (1996).

10. J. Liang, X. Ai, Z. He, H. Xie and D. Pang, Mater. Lett., 59, 2778, (2005).

11. A. P. Soldatkin, J. Montoriol, W. Sant, C. Martelet, N. Jaffrezic-Renault, Talanta, 58, (2), 351, (2002).

12. D. M. Im, D. H. Jang, S. M. Oh, Ch. Striebel, H.-D. Wiemhöfer, G. Gauglitz and W. Göpel, Sens. Actuators B., 24-25, 149, (1995).

13. T. Ignat, M. Miu, I. Klepa, A. Bragaru, M. Simion and M. Danila, Mater. Sci. Eng. B., 169, 55, (2010).

14. A. F. Diaz, J. I. Castillo, J. A. Logan and W. Y. Lee, J. Electroanal. Chem., 129, 115, (1981).

15. J. Tietje-Girault, C. Ponce De Leon and F. C. Walsh, Surf. Coat. Technol., 201, 6025, (2007).

16. C. E. Schmidt, J. M. Fonner, L. Forciniti, H. Nguyen, J. D. Byrne, Y. F. Kou and J. Syeda-Nawaz, Biomed. Mater., 3, 034124, (2008).

17. J. C. Myland and K. B. Oldham, J. Electroanal. Chem., 575, 81, (2005).

18. T. Ahuja, I. A. Mir, D. Kumar and Rajesh, Sens. Actuators B, 134 (1), 140, (2008).

19. T. Yuan, Y. Huang, S. Dong, T. Wang and M. Xie, Polymer Testing, 21, 641, (2002).

20. F.-W. Zeng, X.-X. Liu, D. Diamond and K. T. Lau, Sens. Actuators B., 143, 530, (2010).

21. G. G. Wallace, G. M. Spinks, L. A. P. Kane-Maguire and P. R. Teasdale, Conductive Electroactive Polymers: Intelligent Materials Systems, CRC Press, 237, (2003).

22. H. Larsericsdotter, S. Oscarsson and J. Buijs, J. Colloid and Interface Science, 289, 26, (2005).

23. A. L. Brisena, A. Baca, Q. Z. Zhou, R. Lai and F. M. Zhou, Anal. Chim. Acta, 441, 123, (2001). 
24. G. Maia, R. M. Torresi, E. A. Ticianelli and F. C. Nart, J. Phys. Chem., 100, 15910, (1996).

25. J. R. Macdonald, Annals Biomed. Eng., 20, 289, (2005).

26. V. D. Patake, S. S. Joshi, C. D. Lokhande and O.-S, Joo, Mater. Chem. Phys., 114, 6, (2009).

27. S. Suematsu, Y. Oura, H. Tsujimoto, H. Kanno and K. Naoi, Electrochimica Acta, 45, 3813, (2000).

28. B.-X. Zou, Y. Liang, X.-X. Liu, D. Diamond and K.-T. Lau, J. Power Sources, 196, 4842, (2011).

29. S. Asavapiriyanont, G. K. Chandler, G. A. Gunawardena and D. Pletcher, J. Electroanal. Chem., 177, 229, (1984).

30. M. Zhou and J. Heinze, J. Phys. Chem. B, 103, 8443, (1999).

31. S. Shimoda and E. Smela, Electrochimica Acta, 44, 219, (1998).

32. S. Kuwabata, J. Nakamura and H. Yoneyama, J. Chem. Soc.-Chem. Comm., 779, (1988). 